\title{
Characterization of the Proteins Purified with Monoclonal Antibodies to Glutamic Acid Decarboxylase
}

\author{
Yen-Chung Chang and David I. Gottlieb \\ Department of Anatomy and Neurobiology and the McDonnell Center for Studies of Higher Brain Function, Washington \\ University School of Medicine, St. Louis, Missouri 63110
}

Immunoaffinity columns are prepared from the monoclonal antibody (MAb) GAD-1. These columns are used to enrich glutamic acid decarboxylase (GAD) from the cytosolic fraction of rat brain homogenates and from Triton $X-100$ extracts of the brain membrane fraction. In each case enzyme activity is enriched over $\mathbf{4 0 0}$-fold. The immunopurified fractions were analyzed by SDS-PAGE. Fractions purified from the cytosol consisted of a quantitatively major band of $59 \mathrm{kDa}$, and one band of $63 \mathrm{kDa}$, as well as a group centered around $55 \mathrm{kDa}$. Fractions purified from membranes consisted primarily of the 59 and $63 \mathrm{kDa}$ components; only traces of the lowermolecular-weight components were present. The entire set of proteins purified on GAD-1 immunoaffinity columns is strongly recognized by 2 widely used antisera to GAD, those described in Saito et al. (1974) and Oertel et al. (1981).

The $59 \mathrm{kDa}$ protein from the cytosolic fraction was purified to homogeneity by preparative SDS-PACE; a partial amino acid sequence of this protein was obtained. The $59 \mathrm{kDa}$ protein has a high degree of sequence homology with the deduced amino acid sequence of the protein that was coded for by a CDNA for feline GAD (Kaufman et al., 1986; Kobayashi et al., 1987). Thus, these proteins are either products of a single gene that diverged during the evolution of rat and cat from a common ancestor, or are members of a closely related set of genes found in both species.

The MAb GAD-6 recognizes the $59 \mathrm{kDa}$ band and the group of bands centered around 55 kDa on Western blots. Therefore, these proteins are immunochemically related. GAD-6 does not recognize the $63 \mathrm{kDa}$ band. In Western blots of unfractionated homogenates of the whole brain, the only band recognized by GAD-6 is a 59 kDa band. This argues that the $59 \mathrm{kDa}$ band is found in the living brain and is not a degradative form generated during purification.

\footnotetext{
Received July 16, 1987; revised Oct. 22, 1987; accepted Oct 26, 1987.

We wish to thank Dr. Allan J. Tobin (UCLA) for generously sharing sequence data on the feline GAD cDNA prior to publication and for many points of advice. Drs. Donald E. Schmechel (Duke) and James E. Vaughn (City of Hope Research Institute) provided anti-GAD antisera. Dr. David L. Martin (SUNY) tested the immunoreactivity of our purified GAD samples. Special thanks go to Steven Mick for excellent technical assistance and to David McCourt for amino acid sequence analysis. Supported by NINCDS Grant NS12867 and by a grant from the Monsanto Corporation. Y.-C.C. was supported by a fellowship from the McDonnell Center for Cellular and Molecular Neurobiology.

Correspondence should be addressed to David Gottlieb, Department of Anatomy and Neurobiology, Washington University School of Medicine, 660 South Euclid Avenue, St. Louis, MO 63110.
}

Copyright $(\odot) 1988$ Society for Neuroscience $0270-6474 / 88 / 062123-08 \$ 02.00 / 0$
Glutamic acid decarboxylase (GAD) is the enzyme that catalyzes the synthesis of the neurotransmitter GABA from its precursor, L-glutamic acid. Although the functional importance of GAD has been appreciated for a long time, major questions about the enzyme's structure and subcellular distribution remain unanswered. GAD was first extensively purified by Roberts and his colleagues using mouse brain as a starting material (Wu et al., 1973). SDS-PAGE of the most purificd fraction showed that it contained 7 protein bands with apparent molecular weights ranging from 15 to $118 \mathrm{kDa}(\mathrm{Wu}, 1976)$. On the basis of these data it was proposed that GAD consisted of homomultimers of the $15 \mathrm{kDa}$ protein. Subsequently, GAD was purified from the rat brain by $\mathrm{Wu}$ and his colleagues. The most extensively purified material consists of polypeptides of 40 and $80 \mathrm{kDa}$ (Denner et al., 1987). The relationship of these proteins to those purified from the mouse has not been investigated. Spink et al. (1985) proposed that GAD purified from the hog brain consisted of a single polypeptide of $60 \mathrm{kDa}$. Recently Legay et al. (1987a, b) have described a monoclonal antibody $(\mathrm{MAb})$ to rat brain GAD that precipitates proteins of 59 and $63 \mathrm{kDa}$. Thus, there is a wide discrepancy among proposals for the structure of GAD in the literature.

In spite of the uncertainty, 2 antisera to GAD have been raised and extensively used to localize the enzyme in the nervous system. The first (Saito et al., 1974) was raised against the enzyme purified from the mouse brain cited above. The second was prepared by making an antiserum against partially purified rat brain $\mathrm{GAD}$, immunoprecipitating GAD activity, and preparing a secondary antibody against the immunoprecipitated enzyme (Oertel et al., 1981). These antisera recognize a group of polypeptides in the 55-65 kDa range (Kaufman et al., 1986). The exact relationship of these bands to enzymatically active GAD has not been established. Nevertheless, the antibodies have been extensively used to map GABAergic neurons.

We recently selected 5 MAbs that recognize GAD from the chicken brain (Gottlieb et al., 1986). Two of these MAbs, GAD-1 and GAD-2, also recognize GAD from the rat brain. The antigen recognized by GAD-1 and 2 is highly enriched in the central nervous system relative to other tissues. GAD-1 and 2 selectively stain neurons that have been shown to be GABAergic. Immunoaffinity columns of GAD-1 were used to obtain highly enriched preparations of GAD. These preparations consisted of a group of proteins as seen on SDS-PAGE. The quantitatively major band had an apparent molecular weight of $59 \mathrm{kDa}$. A second band of $63 \mathrm{kDa}$ and a group of bands centered about 55 $\mathrm{kDa}$ were also present in all purified fractions. This polypeptide composition is in striking agreement with the structure of GAD put forward by Legay et al. (1986, 1987a, b). 
In order to help clarify the structure of GAD, we have investigated the proteins recognized by the GAD-1 MAb. The 59 $\mathrm{kDa}$ protein has been purified and partially sequenced. The sequence shows a striking homology to that derived from a cDNA coding for feline brain GAD isolated and characterized by Tobin and his colleagues (Kaufman et al., 1986; Kobayashi et al., 1987). Western blots of the GAD-1-purified proteins show that they are strongly recognized by the anti-GAD antibodies of Saito et al. (1974) and Oertel et al. (1981). A new MAb, GAD-6, is also described. GAD-6 selectively recognizes the 59 $\mathrm{kDa}$ protein on Western blots. These data are used to derive a model for the structure of GAD from the adult rat brain. Portions of these results have appeared in abstract form (Chang and Gottlieb, 1987).

\section{Materials and Methods}

Frozen chicken brains were purchased from Pel Freez. Rat brains were from Sprague-Dawley rats and were frozen in liquid nitrogen and stored at $-70^{\circ} \mathrm{C}$ until ready for use. $\mathrm{L}-\mathrm{U}-{ }^{14} \mathrm{C}$ - and $\mathrm{L}-1-{ }^{14} \mathrm{C}$-glutamic acid were purchased from New England Nuclear. Affi-Gel 10 was from Bio-Rad.

Assay for GAD activity and protein determination. GAD activity was determined by measuring the quantity of $\mathrm{CO}_{2}$ released from ${ }^{14} \mathrm{C}$ uniformly labeled glutamic acid by established methods (Roberts and $\mathrm{Si}$ monsen, 1963; Molinoff and Kravitz, 1968). In many assays we performed parallel measurements using ${ }^{14} \mathrm{C}$-glutamate labeled only at the 1 position. This control shows that all $\mathrm{CO}_{2}$ evolved is from the one position and that generation of $\mathrm{CO}_{2}$ from more distal carbons does not occur under our assay conditions. Occasionally GABA generated in the assay was measured directly on an amino acid analyzer and shown to be produced in stoichiometric amounts with $\mathrm{CO}_{2}$. In the kinetic studies of pure GAD, BSA at $1 \mathrm{mg} / \mathrm{ml}$ was included to stabilize the enzyme. Protein concentration was determined by the Bradford method (Bradford, 1976).

Purification of GAD from rat brains. Rat brains (60 gm) were homogenized with a Polytron homogenizer in $340 \mathrm{ml}$ of distilled water containing $1 \mathrm{mM}$ AET, $0.2 \mathrm{~mm}$ PLP, $1 \mathrm{~mm}$ phenylmethylsulfonyl fluoride (PMSF), and $0.2 \mathrm{~mm}$ EDTA. The homogenate was centrifuged at $130,000 \times g$ for $70 \mathrm{~min}$ and the supernatant removed for further processing. Then $157 \mathrm{gm} /$ liter of solid ammonium sulfate was added to the supernatant; precipitated proteins were removed by centrifugation and discarded. The ammonium sulfate concentration of the supernatant was raised to $289 \mathrm{gm} /$ liter and the precipitate collected, dissolved in standard buffer ( $50 \mathrm{mM} \mathrm{KPO}_{4}, 1 \mathrm{~mm}$ AET, $\left.0.2 \mathrm{~mm} \mathrm{PLP}, \mathrm{pH} 7.2\right)$, and dialyzed against standard buffer. Purification of the enzyme on GAD-1 affinity columns was as described in Gottlieb et al. (1986) for the enzyme from chicken brain. To purify GAD associated with membranes, the membrane pellet obtained above was used as starting material. This pellet was washed twice in $5 \mathrm{mM} \mathrm{KPO}_{4}$, pH 7.2, containing $1 \mathrm{~mm}$ AET, $0.2 \mathrm{~mm}$ PLP, $2 \mathrm{~mm}$ PMSF, and $0.2 \mathrm{~mm}$ EDTA. The pellet was finally extracted with $250 \mathrm{ml}$ of the same buffer containing $0.2 \%$ Triton $\mathrm{X}-100$ for $1 \mathrm{hr}$ at $12^{\circ} \mathrm{C}$. The extract was then centrifuged at $100,000 \times g$ for $70 \mathrm{~min}$ and the supernatant removed for further processing. The supernatant was then run over GAD-1 columns as described above for the cytosolic enzyme.

Gel-permeation HPLC of GAD. Immunoaffinity-purified GAD was chromatographed on a gel-permeation HPLC column (PAK 300 SW; Waters; $7.5 \mathrm{~mm} \times 30 \mathrm{~cm}$ ). The column was eluted with standard buffer plus $0.5 \%$ Triton $X-100$ at a flow rate of $1 \mathrm{ml} / \mathrm{min}$.

Isolation of the $59 \mathrm{kDa}$ protein by preparative $S D S-P A G E$. The 59 $\mathrm{kDa}$ protein was isolated from preparative SDS gels by the procedure of Hunkapiller et al. (1983), with some modification. Immunoaffinitypurified GAD was loaded onto $8 \%$ polyacrylamide slab gels $(14 \times 15 \times$ $0.3 \mathrm{~cm}$ ). After electrophoresis at $150 \mathrm{~V}$ for $5 \mathrm{hr}$ the bands were visualized by staining with $4 \mathrm{~N}$ sodium acetate. The $59 \mathrm{kDa}$ band was cut out of the gel and the gel pieces transferred to an electrophoretic sample concentrator (Isco, Model 1750). After electrophoresis, the recovered proteins were concentrated by lyophilization. Recovery was approximately $90 \%$.

$\mathrm{CnBr}$ cleavage of the $59 \mathrm{kDa}$ protein. Purified $59 \mathrm{kDa}$ protein, 250 $\mu \mathrm{g}$, was dissolved in $1 \mathrm{ml}$ of $75 \%$ triftuoroacetic acid (TFA) containing $30 \mathrm{mg}$ of $\mathrm{CnBr}$ and kept under a nitrogen atmosphere for $18 \mathrm{hr}$. The mixture was then diluted with $36 \mathrm{ml}$ of water and lyophilized. The lyophilized peptides were dissolved in $0.5 \mathrm{ml}$ of $0.05 \%$ TFA and chromatographcd on a C-18 Microbondpak column (Waters). The column was eluted with a $0-100 \%$ acetonitrile gradient in $0.05 \%$ TFA at a flow rate of $0.5 \mathrm{ml} / \mathrm{min}$ for $200 \mathrm{~min}$, and $0.5 \mathrm{ml}$ fractions were collected.

Sequence analysis of peptides. Edman degradation of peptides was performed on an Applied Biosystems Model 470A protein sequencer. TFA-treated glass-fiber filters were used and the peptide immobilized with $1.5 \mathrm{mg}$ Biobrene Plus. All chemicals were purchased from ABI and the standard degradation run (03 RPTH) was used.

Phenylthiohydantoin (PTH) amino acids were analyzed with the online Model 120A PTH analyzer (ABI). The standard $220 \times 2 \mathrm{~mm} \mathrm{PTH}$ $\mathrm{C}-18$ column was used at $55^{\circ} \mathrm{C}$ with a $50 \mu$ injection loop. The standard gradient with slight modifications was used.

Immunization of mice and hybridoma production. The monoclonal antibody GAD-6 was obtained by immunizing a mouse with $300 \mu \mathrm{g}$ of rat brain GAD immunoaffinity-purified on a GAD-1 column in complete Freund's adjuvant and boosting 1 month later with $300 \mu \mathrm{g}$ of the same protein in incomplete Freund's adjuvant. Hybridomas were prepared by our standard methods and screened for their ability to recognize GAD on Western blots (Schwob and Gottlieb, 1986). The GAD-6 line was cloned by limiting dilution, and was used to generate ascites fluid.

Other methods. SDS-PAGE analysis was carried out according to Laemmli (1970). Immunoblots were prepared as detailed in Schwob and Gottlieb (1986).

\section{Results \\ Immunopurification of cytosolic GAD (C-GAD) and membrane-associated $G A D(M-G A D)$ from rat brain}

When rat brains were homogenized under our standard conditions, approximately $60 \%$ of the enzyme activity was distributed with the membrane fraction sedimented at $100,000 \times g$, while $40 \%$ remaincd in the supernatant. Most of the membraneassociated GAD activity (M-GAD) can be solubilized in buffer containing $0.2 \%$ Triton $X-100$. The nature of the association of $\mathrm{M}-\mathrm{GAD}$ with membranes is investigated below. Table 1 summarizes the immunoaffinity purification of cytosolic GAD (CGAD) and M-GAD. In each case, enzyme activity is purified over 400 -fold. A total of $16.7 \%$ of the starting enzymatic activity is obtained in the column eluates. There are 2 reasons to believe that this is an underestimation of the fraction of GAD activity recognized by the GAD-1 MAb. The first is that, in separate experiments in which GAD is briefly exposed to high $\mathrm{pH}$, enzymatic activity is lowered by about $50 \%$. The second is that if GAD activity in the flowthrough fraction is reapplied to a GAD-1 column, a considerable portion binds. While it is not possible to show rigorously what percentage of GAD activity is recognized by GAD-1, it is likely to be much higher than the $16.7 \%$ that actually appears in Table 1.

Several properties of the enzyme purified in Table 1 are comparable with GAD purified by others. Purified mouse brain GAD has a specific activity of $3 \mu \mathrm{mol} / \mathrm{min} / \mathrm{mg}$ (Wu et al., 1973); that from the hog brain has a specific activity of $0.7 \mu \mathrm{mol} / \mathrm{min} /$ $\mathrm{mg}$ (Spink et al., 1985). The specific activity of $2.5 \mu \mathrm{mol} / \mathrm{min} /$ mg found for GAD-1 immunoaffinity-purified enzyme compares favorably with these values, especially considering the inactivation that probably occurs during the high-pH elution step. The $K_{t 11} \mathrm{~s}$ for glutamate are $1.2 \mathrm{~mm}$ for C-GAD and 1.5 $\mathrm{mM}$ for M-GAD, values that are comparable to those in the literature.

The protein composition of purified C-GAD and M-GAD is illustrated in Figure 1. Both preparations have a dominant band of $59 \mathrm{kDa}$ and a less intensely staining band at $63 \mathrm{kDa}$. C-GAD also has a triplet of bands centered about $55 \mathrm{kDa}$. These lower bands are present but much less intense in the M-G $\Lambda D$ preparation. The protein composition of C-GAD is indistinguishable 
Table 1. GAD-1 immunoaffinity purification of cytosolic and membrane-associated rat brain GAD

\begin{tabular}{lcccc} 
& & $\begin{array}{l}\text { Total } \\
\text { activity } \\
(\mu \mathrm{mol} / \mathrm{min})\end{array}$ & $\begin{array}{l}\text { Specific } \\
\text { activity } \\
(\mathrm{nmol} / \\
\mathrm{mg} / \mathrm{min})\end{array}$ & $\begin{array}{l}\text { Activity } \\
\text { recovery } \\
(\%)\end{array}$ \\
\hline Cytosolic & Protein $(\mathrm{mg})$ & & \\
Brain homogenate & & & & \\
Supernate of homogenate & 3760 & 22.18 & 5.9 & 100 \\
Ammonium sulfate fraction & 1147 & 9.06 & 7.9 & 40.8 \\
Flowthrough from affinity column & 779 & 7.24 & 9.3 & 32.6 \\
High-pH buffer elution from affinity column & 643 & 2.06 & 3.2 & 9.3 \\
Membrane Associated & 0.82 & 2.04 & 2490 & 9.2 \\
Brain homogenate & & & & \\
Pellet of homogenate & 3928 & 20.03 & 5.1 & 100 \\
Pellet after 1st wash & 2770 & 13.30 & 4.8 & 66.4 \\
Pellet after 2nd wash & 2416 & 10.87 & 4.5 & 54.3 \\
0.2\% Triton X-100 extraction & 2235 & 8.49 & 3.8 & 42.4 \\
Flowthrough from affinity column & 587 & 5.64 & 9.6 & 28.2 \\
High-pH buffer elution from affinity column & 596 & 1.79 & 3.0 & 8.9 \\
\hline
\end{tabular}

Rat brain membrane homogenates, supernatants, and 100,000 $\times g$ membrane pellets were prepared as described in Materials and Methods. For cytosolic GAD, the starting material for immunoaffinity purification was an ammonium sulfate fraction. For membrane-associated GAD, a $0.2 \%$ Triton X-100 extract of the pellet was used. Enzyme-containing extracts were passed over the GAD-1 affinity column and the enzyme eluted as described in Materials and Methods.

from that described for cytosolic GAD from the chicken brain (Gottlieb et al., 1986).

Proteins purified by GAD-1 are recognized by 2 widely used antisera to $G A D$

Two antisera to GAD have been used extensively to localize GAD immunohistochemically: those produced against mouse brain GAD (Saito et al., 1974) and against rat brain GAD (Oertel et al., 1981). To determine whether the proteins purified by GAD- 1 are related to those recognized by these 2 antisera, Western blot analysis on the GAD-1-purified proteins from the cytosol was performed (Fig. 2). The results show that each antiserum recognizes all of the protein bands in the GAD-1-purified material. Thus, these proteins are clearly immunologically related to those used as the original antigens. Whether they are identical or simply homologous cannot be ascertained from these data. The fact that all the bands stain could be due either to their sharing epitopes or to the fact that they all copurified when the original antigens were purified. The significance of the bands of high molecular weight in lanes 2 and 3 is not understood. In summary, this analysis shows that GAD, as detected previously with polyclonal antisera, and as detected by GAD-1, is very much the same immunologically. The proteins recognized by GAD-1 are also immunologically related to the GAD purified in the laboratory of Dr. David L. Martin (SUNY) (D. L. Martin, personal communication).

\section{High-pressure liquid chromatography $(H P L C)$ gel-permeation chromatography of cytosolic GAD}

The relationship between the protein bands in Figure 1 and GAD activity would be strengthened by demonstrating comigration on an independent chromatographic system. Therefore, we chromatographed immunoaffinity-purified C-GAD on an HPLC gel-exclusion column and analyzed fractions for activity and for protein composition on SDS-PAGE (Fig. 3). Activity and the complex of bands clearly comigrated. Attempts to sep-

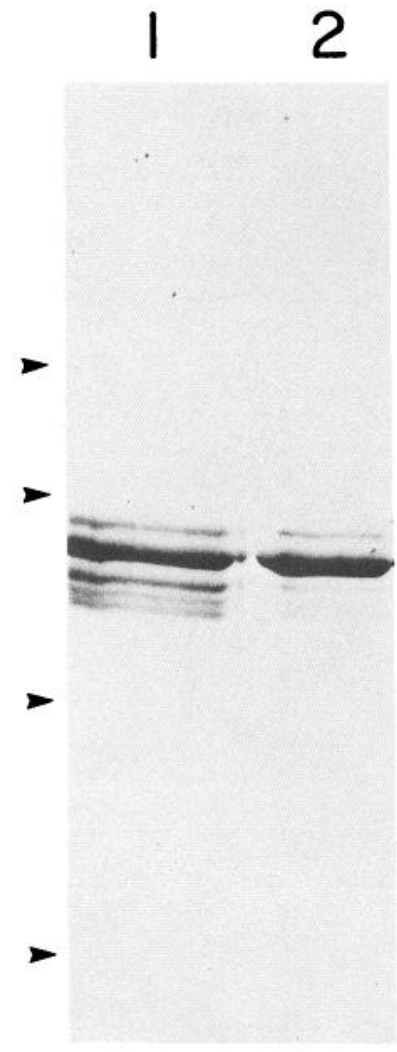

Figure 1. SDS-PAGE analysis of cytosolic and membrane-associated GAD. GAD was purified from either the cytosolic or membrane fractions, as detailed in Table 1. The high-pH buffer elution fraction from each purification was concentrated and loaded onto a lane of a 9\% SDS gel. Lane $1,6 \mu \mathrm{g}$ of purified cytosolic fraction. Lane $2,9.8 \mu \mathrm{g}$ of purified membrane-associated fraction. Molecular-weight markers, indicated by the arrowheads, are 93, 66, 45, and $21 \mathrm{kDa}$. Gel is stained with Coomassie blue. 


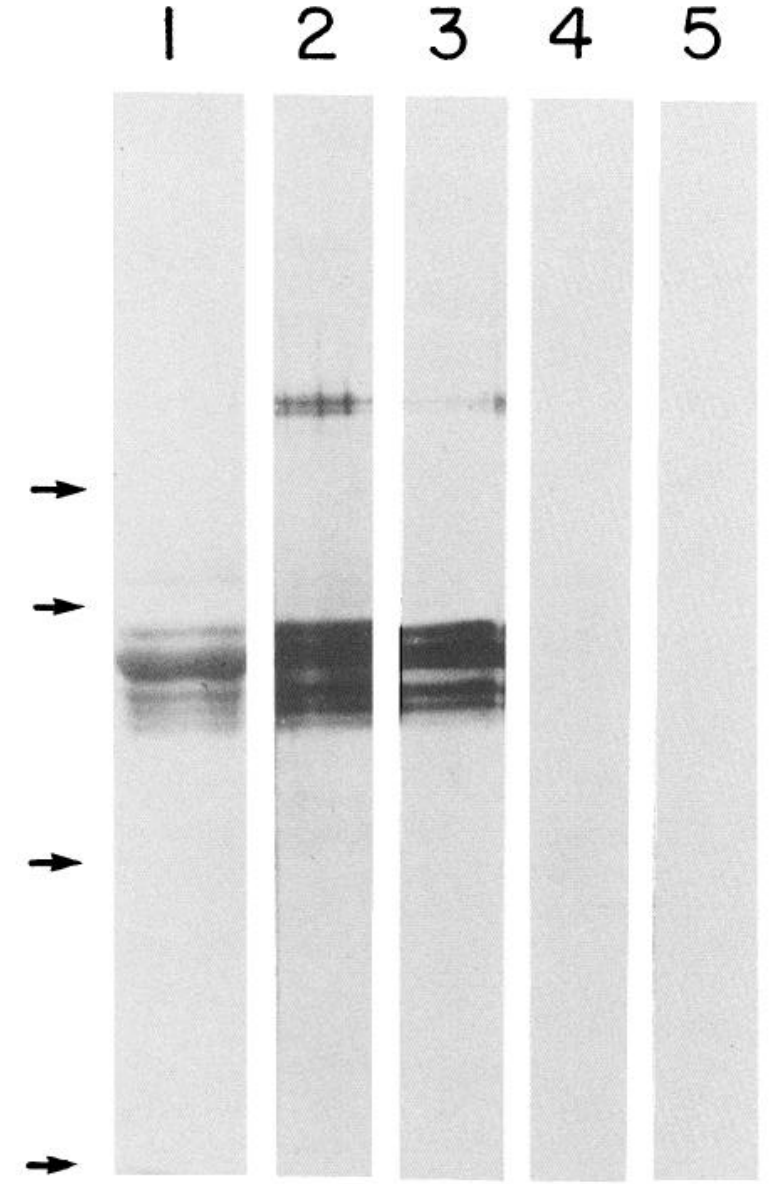

Figure 2. Immunoaffinity-purified GAD reacts with 2 widely used antisera to GAD. Rat brain GAD immunoaffinity-purified on a GAD-1 column is analyzed by the Western blot technique. SDS-PAGE gel lanes are loaded with the following amounts of purified GAD: lane $1,4 \mu \mathrm{g}$; lanes $2-5,0.2 \mu \mathrm{g}$. The gel is run and then transferred to nitrocellulose. Lane $I$ is stained with Amido black. Primary antisera: lane 2, 1:2000 dilution of sheep anti-GAD (Oertel et al., 1981); lane 4, 1:2000 dilution of sheep preimmune serum; lane 3, 1:400 dilution of rabbit anti-GAD (Saito et al., 1974); and lane 5, 1:400 dilution of normal rabbit serum. Lanes were then stained with appropriate secondary reagents. Arrows refer to the same molecular-weight markers as in Figure 1. arate bands from one another using DEAE-HPLC or hydrophobic interaction chromatography were unsuccessful. This suggests that either these proteins are tightly associated with one another or they share many physical properties.

\section{Partial amino acid sequence of the $59 \mathrm{kDa}$ protein}

Tobin and his co-workers (Kaufman et al., 1986; Kobayashi et al., 1987) have cloned and sequenced a cDNA for feline GAD. In order to understand the relationship of the $59 \mathrm{kDa}$ protein to the feline GAD cDNA, the $59 \mathrm{kDa}$ protein was purified by preparative SDS-PAGE. Figure 4 shows the purified $59 \mathrm{kDa}$ protein obtained after this purification procedure. The $\mathrm{N}$-terminus of this protein proved to be blocked; thus, to determine amino acid sequence, the protein was cleaved by cyanogen bromide and cleavage peptides separated by reverse-phase HPLC. Twelve peptide peaks were sequenced. Of these, 8 gave unique sequences, while 4 were complete or partial overlaps. It is immediately apparent that there is a strong homology between the protein sequence deduced from the feline cDNA and the sequence from the rat $59 \mathrm{kDa}$ protein. The data are presented in Table 2 by aligning the protein sequence obtained with the deduced feline sequence. Every peptide sequenced has at least partial homology. The peptides sequenced totaled 97 amino acids in length. They are aligned with 3 contiguous sections of the deduced feline sequence. Sixty-eight of the 97 amino acids in the aligned sequences are identical. Furthermore, there are relatively long identical sequences, including one of 12 , one of 10 , one of 8 , and one of 5 amino acids. Of the 29 nonidentical amino acids, 17 could be derived by a single base-pair substitution. The possible explanations for the similarities and differences between these sequences are taken up in the Discussion.

\section{$M A b G A D-6$ selectively recognizes the $59 \mathrm{kDa}$ protein}

MAbs GAD-1-5 were selected on the basis of their ability to immunoprecipitate active GAD. Unfortunately, they do not stain GAD on Western blots, presumably because they recognize conformations lost in the process of SDS-PAGE. Thus, GAD-6 was selected on the basis of its ability to stain purified GAD on Western blots. Figure 5 illustrates that GAD-6 stains the $59 \mathrm{kDa}$ bands of both C-GAD and M-GAD intensely (lanes 6 and 8 ).

Table 2. Comparison of GAD sequence deduced from feline cDNA GAD and determined by sequencing of peptides from rat $59 \mathrm{kDa}$ protein

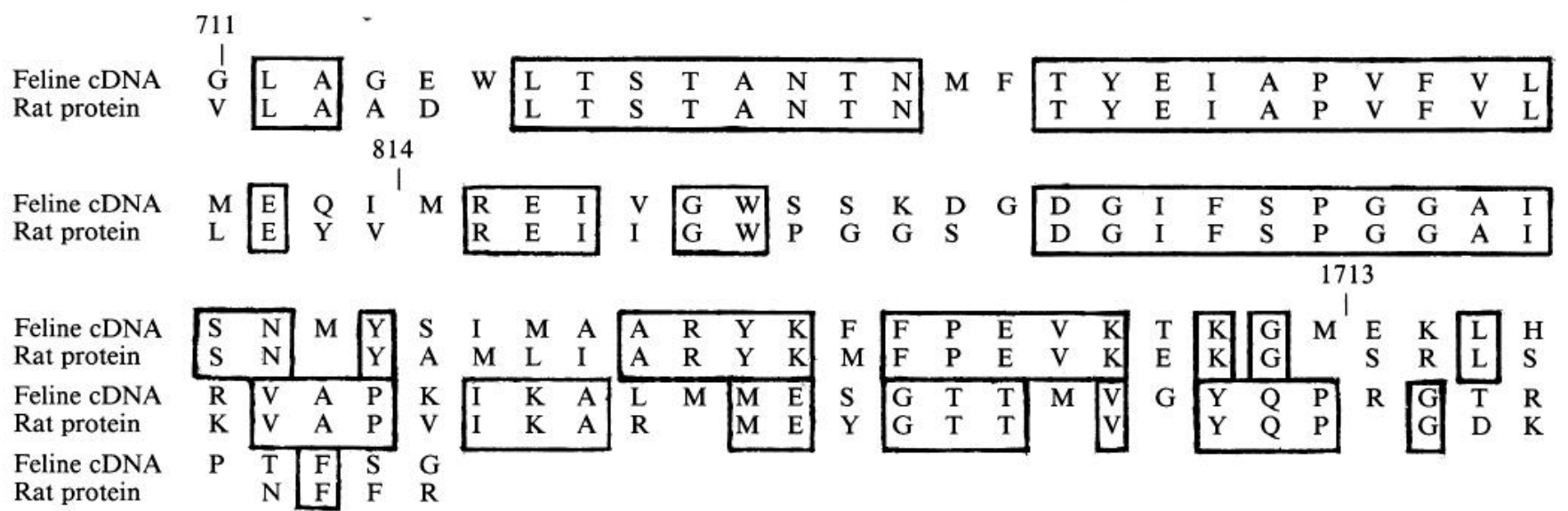

The feline cDNA sequence is taken from Kobayashi et al. (1987). Rat protein sequences were obtained from the $59 \mathrm{kDa}$ protein as described in Materials and Methods. Numbers give the position in the sequence of the first nucleotide encoding for the corresponding amino acid. Breaks in the feline cDNA sequence are indicated by

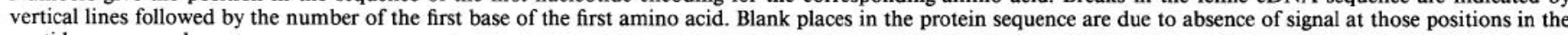
peptides sequenced. 
Table 3. GAD activity $(\mu \mathrm{mol} / \mathrm{min})$

\begin{tabular}{lllllll} 
& Homogenate & Supernatant & Pellet & \\
\hline Control & $0.49 \pm 0.01$ & $(100 \%)$ & $0.06 \pm 0.01$ & $(12 \%)$ & $0.44 \pm 0.01$ & $(90 \%)$ \\
$\mathrm{NaCl}(1 \mathrm{~N})$ & $0.41 \pm 0.01$ & $(100 \%)$ & $0.05 \pm 0.01$ & $(12 \%)$ & $0.54 \pm 0.01$ & $(132 \%)$ \\
$\mathrm{KCl}(1 \mathrm{~N})$ & $0.52 \pm 0.01$ & $(100 \%)$ & $0.09 \pm 0.01$ & $(17 \%)$ & $0.57 \pm 0.01$ & $(110 \%)$ \\
$\mathrm{EDTA}(15 \mathrm{~mm})$ & $0.49 \pm 0.02$ & $(100 \%)$ & $0.04 \pm 0.01$ & $(8 \%)$ & $0.47 \pm 0.02$ & $(96 \%)$ \\
$\mathrm{KPO}_{4}(0.5 \mathrm{M})$ & $0.52 \pm 0.01$ & $(100 \%)$ & $0.07 \pm 0.01$ & $(13 \%)$ & $0.48 \pm 0.01$ & $(92 \%)$ \\
Triton X-100 $(0.2 \%, \mathrm{vol} / \mathrm{vol})$ & $0.80 \pm 0.03$ & $(100 \%)$ & $0.57 \pm 0.02$ & $(71 \%)$ & $0.32 \pm 0.02$ & $(40 \%)$ \\
\hline
\end{tabular}

Rat brains $(10 \mathrm{gm})$ were homogenized with $57 \mathrm{ml}$ of a solution containing $0.2 \mathrm{~mm}$ PLP, $2 \mathrm{~mm} \mathrm{AET}, 2 \mathrm{~mm}$ PMSF, and $0.2 \mathrm{~mm}$ EDTA at pH 7.2. Homogenates were pelleted by centrifugation $(100,000 \times g$ for 70 min), and the resultant pellet was washed twice by the following procedure: pellets homogenized in $50 \mathrm{ml}$ of washing solution ( $5 \mathrm{nM} \mathrm{KPO}_{4} 0.2$ $\mathrm{mm}$ PLP, pH 7.2, and $2 \mathrm{~mm}$ AET), and the homogenate centrifuged at $100,000 \times \mathrm{g}$ for $70 \mathrm{~min}$. Washed pellets were then homogenized with $40 \mathrm{ml}$ of washing solution (control) or with $40 \mathrm{ml}$ of washing solution containing $\mathrm{NaCl}$ (1 $\mathrm{N}$ ), $\mathrm{KCl}(1 \mathrm{~N})$, EDTA $(15 \mathrm{nM}), \mathrm{KPO}_{4}(495 \mathrm{~nm})$, or Triton X-100 $(0.2 \% \mathrm{vol} / \mathrm{vol})$. The resultant homogenates were incubated with shaking at $6^{\circ} \mathrm{C}$ for $1 \mathrm{hr}$ and then separated into supernatant and pellet fractions by centrifugation $(100,000 \times g$, $70 \mathrm{~min}$ ). Aliquots of homogenates before the final centrifugation, supernatants, and pellets were dialyzed against standard buffer overnight and then assayed for GAD activity. Activity is expressed as $\mu \mathrm{mol} \mathrm{CO}_{2}$ generated per minute for the entire fraction.

It stains 2 lower-molecular-weight bands to a much lesser extent. Most notably, it does not stain the $63 \mathrm{kDa}$ band in either C-GAD or M-GAD. Therefore, there is at least one epitope that is found on the $59 \mathrm{kDa}$ protein that is either missing or cryptic in the $63 \mathrm{kDa}$ protein. The results also show that the $59 \mathrm{kDa}$ band is present in whole brain homogenates that are quickly denatured in SDS (lane 4). This argues strongly that the $59 \mathrm{kDa}$ band is present as such in the intact brain and is not generated from a larger protein during purification. The additional highermolecular-weight stained bands in the whole brain homogenate are also found in the corresponding normal mouse serum control (lane 5). Therefore, only the $59 \mathrm{kDa}$ band represents specific staining. Two other properties of GAD- 6 have been discovered (data not shown). It can immunoprecipitate GAD activity from
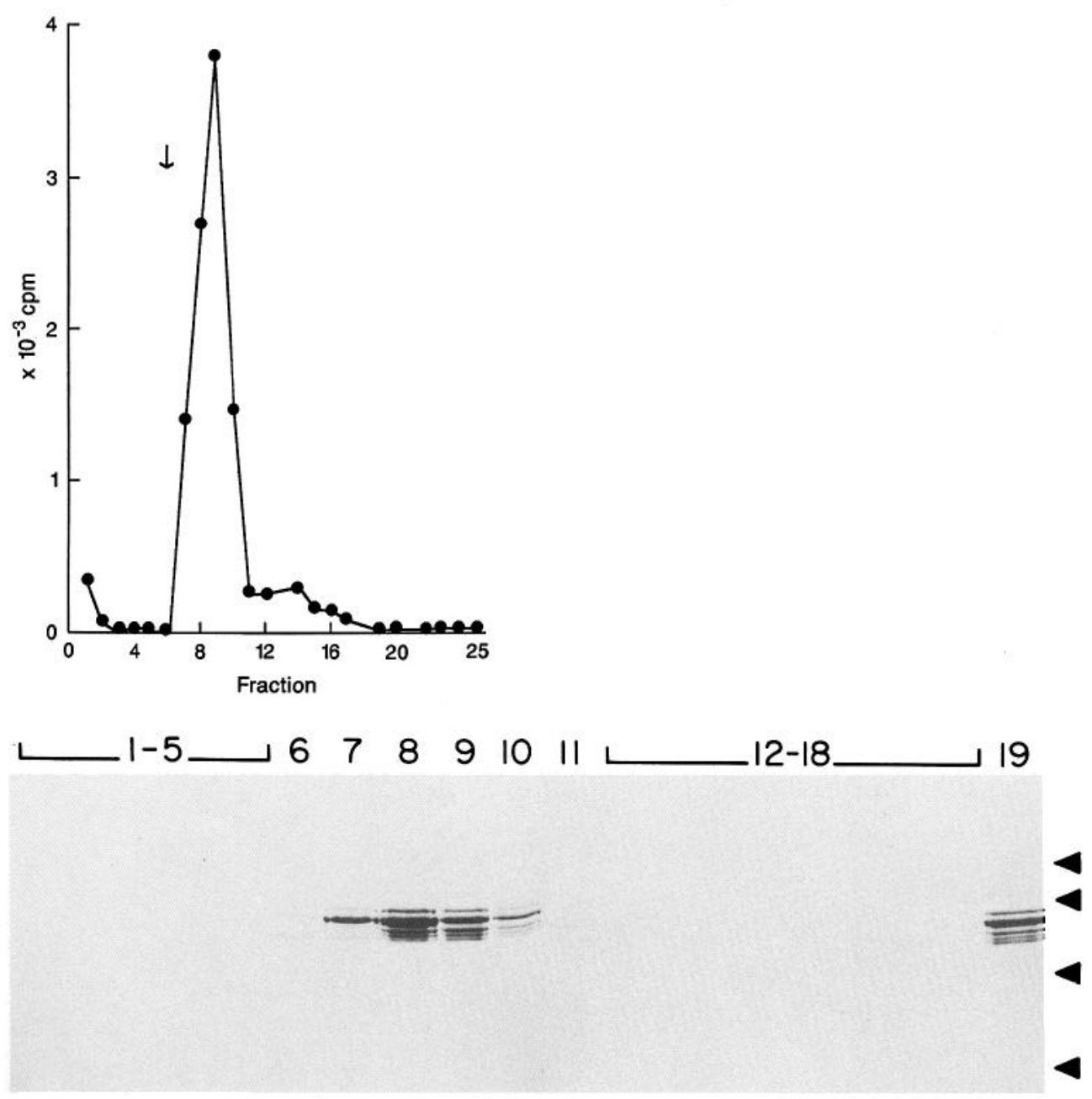

Figure 3. HPLC-gel-permeation chromatography of immunoaffinity column-purified rat brain GAD. Top, Elution profiles of enzyme activity. Fractions of $1 \mathrm{ml}$ are collected. Of each fraction, $0.2 \mathrm{ml}$ is assayed in standard $\mathrm{CO}_{2}$ release assay. The cpm of ${ }^{14} \mathrm{CO}_{2}$ released is plotted for each fraction. $\mathrm{Ar}$ row indicates the position of the blue dextran marker. Bottom, SDS-PAGE analysis of fractions eluted from HPLC. Of each fraction, $0.5 \mathrm{ml}$ was concentrated by chloroform-methanol precipitation and applied to a single lane of a 9\% SDS-polyacrylamide gel. Lanes $1-$ 18 are from the correspondingly numbered fractions. Lane 19 is $2 \mu \mathrm{g}$ of sample originally loaded on the column. The stain is Coomassie blue. Molecularweight markers as in previous figures. 


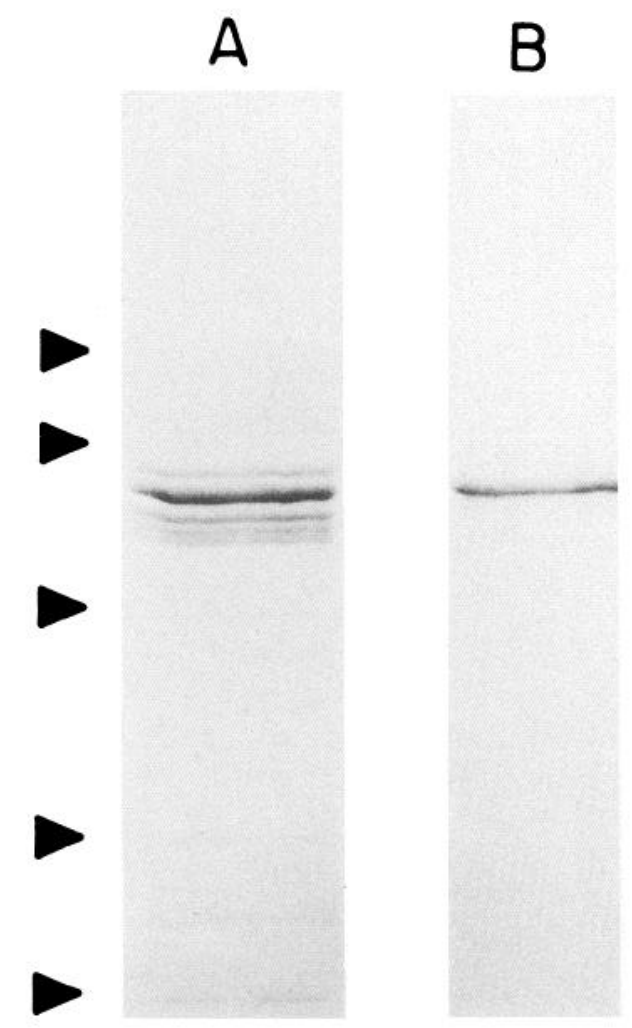

Figure 4. SDS-PAGE analysis of gel-purified $59 \mathrm{kDa}$ protein. The 59 $\mathrm{kDa}$ protein of rat brain cytosol was isolated by immunoaffinity chromatography, preparative SDS-PAGE, and electroelution. Lane $A, 3.5$ $\mu \mathrm{g}$ of immunoaffinity column-purified protein from samples used for further purification. Lane $B, 1.5 \mu \mathrm{g}$ of gel-purified protein. The stain is Coomassie blue and the markers are as in previous figures. solution. Furthermore, an immunoaffinity column of GAD-6 immunopurifies both the 59 and the $63 \mathrm{kDa}$ bands. This suggests that these 2 bands are tightly associated in solution.

\section{Solubilization of $M-G A D$}

Previous studies have noted that, under some conditions, GAD enzymatic activity is associated with membrane fractions (Weinstein et al., 1963; Fonnum, 1968). In the purification described above (see Table 1 and Fig. 1), it was shown that C-GAD and M-GAD are both recognized by the GAD-1 antibody and have a very similar protein composition. These data still allow for the possibility that M-GAD is passively trapped or adsorbed onto membranes in a nonspecific manner. The nature of the association of GAD with membranes was investigated by extracting membranes with various buffers and noting the distribution of GAD activity (Table 3). The results show that homogenization and extraction of pellets with buffers known to remove peripheral membrane proteins $(1 \mathrm{~N} \mathrm{NaCl}, 1 \mathrm{~N} \mathrm{KCl}, 15$ mM EDTA) does not solubilize the GAD activity from brain membranes. There is a marked activation caused by extraction with $\mathrm{NaCl}$ and $\mathrm{KCl}$. However, treatment of pellets with $0.2 \%$ Triton X-100 solubilizes $71 \%$ of the enzyme activity. It is thus likely that GAD is associated with some type of neuronal membranes by a hydrophobic interaction. An intriguing possibility is that at least part of the M-GAD is associated with synaptic vesicles because 2 electron-microscopic studies have noted the morphological association of GAD with synaptic vesicles (McLaughlin et al., 1975; Fisher et al., 1987). Clearly, this issue requires additional investigation. The present results do establish that a quantitatively major form of GAD has some form of association with membranes and that it has a protein composition that is very similar to the cytosolic form of the enzyme.
Figure 5. Western blot analysis of GAD-6 specificity. GAD-6 recognizes the $59 \mathrm{kDa}$ protein, but not the $63 \mathrm{kDa}$ protein. Lanes 1-3 Amido black staining. Lane $1,43 \mu \mathrm{g}$ of whole brain homogenate protein; lane 2, $2 \mu \mathrm{g}$ affinitypurified cytosolic GAD; lane 3, $2 \mu \mathrm{g}$ affinity-purified membrane-associated GAD. Lanes 4, 6, 8, GAD-6 staining. Each lane was stained with GAD-6 at 1:2000 dilution. Lane $4,43 \mu \mathrm{g}$ protein whole brain homogenate; lane $6,0.2 \mu \mathrm{g}$ affinity-purified cytosolic GAD; lane 8 , $0.2 \mu \mathrm{g}$ affinity-purified membrane-associated GAD. Lanes $5,7,9$, normal mouse serum controls. Each lane was stained with normal mouse serum at 1:2000 dilution. Lane $5,43 \mu \mathrm{g}$ of whole brain homogenate protein; lane $7,0.2$ $\mu \mathrm{g}$ affinity-purified cytosolic GAD; lane 9, $0.2 \mu \mathrm{g}$ affinity-purified membraneassociated GAD. Molecular-weight markers are the same as in previous figures.

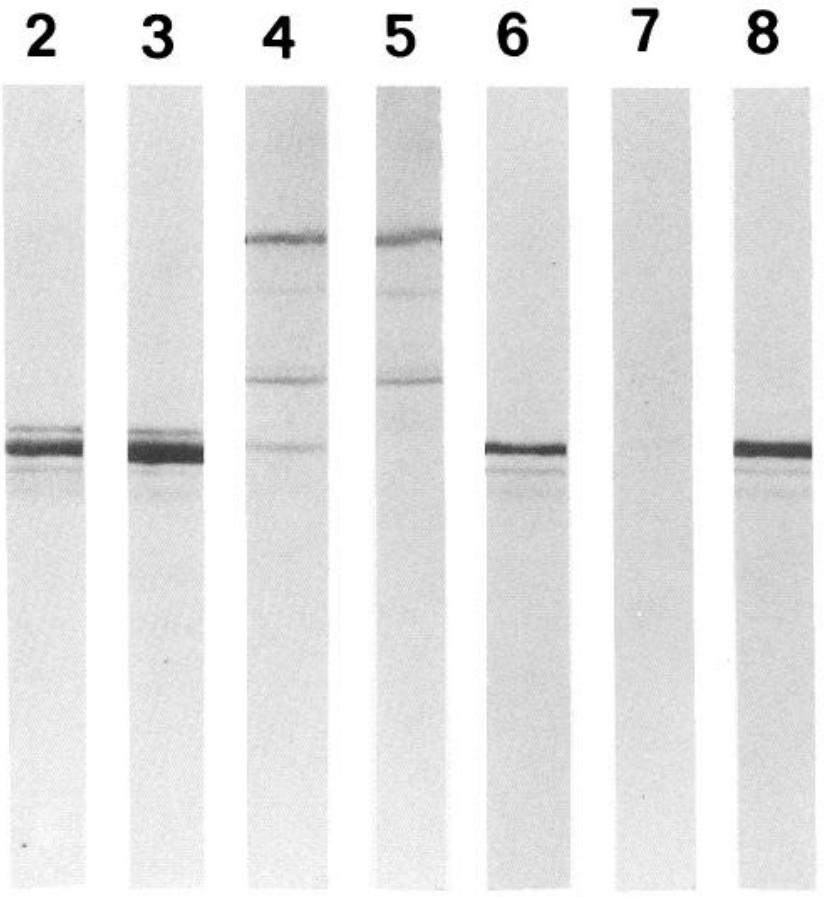

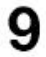

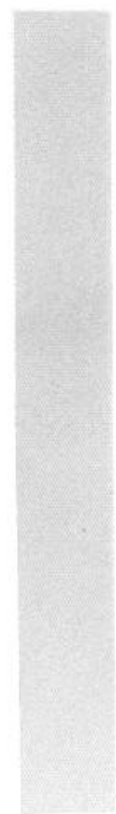




\section{Discussion}

In a previous report, we described the selection and characterization of 5 MAbs to GAD (Gottlieb et al., 1986). Each of these MAbs had the ability to selectively immunoprecipitate the active enzyme from relatively crude brain extracts. Radioimmunoassays revealed that the antigen recognized by GAD-1 was highly enriched in the brain relative to other tissues. Immunohistochemistry with both GAD-1 and GAD-2 showed that the antigen(s) recognized by these MAbs were localized to neurons generally thought to be GABAergic. When the proteins in fractions highly enriched in GAD by immunoaffinity chromatography were analyzed by SDS-PAGE, a characteristic set of bands was observed. The present results extend these observations.

GAD-1 immunoaffinity columns were used to enrich GAD activity from the cytosolic fraction of rat brain homogenates. The most enriched fractions contained a set of proteins indistinguishable from those from the chicken brain. The most prominent band had an apparent molecular weight of $59 \mathrm{kDa}$; there was another band of $63 \mathrm{kDa}$ and a set of about 3 bands centered at $55 \mathrm{kDa}$. Purification from the membrane fraction of rat brain revealed a similar picture: the 59 and $63 \mathrm{kDa}$ proteins were clearly present, while the lower-molecular-weight components were present in much lesser amounts. All attempts to separate these bands in native form by HPLC methods were unsuccessful. The $59 \mathrm{kDa}$ protein was isolated by preparative SDS-PAGE and fractionated by cyanogen bromide cleavage. Sequence analysis revealed that this protein has a strong homology to a feline GAD cDNA (Kaufman et al., 1986; Kobayashi et al., 1987), which has been demonstrated to code for enzymatically active GAD. The homology between the $59 \mathrm{kDa}$ rat protein and the feline protein can be explained in 3 possible ways. The first assumes that there is a single gene for GAD in both cat and rat and that all of the differences between the 2 proteins are due to evolutionary divergence. A second possibility is that cach species has a single gene, but that alternative splicing patterns produce several mRNAs and thus the feline cDNA and the rat $59 \mathrm{kDa}$ protein represent alternative splicing pathways of a single gene. Finally, there is the possibility that there are multiple genes for GAD or GAD-like proteins, and the feline cDNA and rat 59 $\mathrm{kDa}$ protein are the products of related but distinct genes. Further analysis of the immunopurified proteins and the corresponding cDNAs will be necessary to choose among these alternatives. Kobayashi et al. (1987) show that the feline GAD cDNA codes for a protein of $66 \mathrm{kDa}$. The discrepancy between the $59 \mathrm{kDa}$ homologous protein immunoprecipitated by our antibodies and the predicted molecular weight might be due to species differences, anomalous migration of the protein on gels, or the presence of a sequence removed by proteolysis during biosynthesis.

Another goal of this study has been to understand the relationship between the proteins purified using GAD-1 immunoaffinity columns and the forms of the enzyme studied by other workers in the past. Legay et al. $(1987 \mathrm{a}, \mathrm{b})$ have shown that GAD in upper vertebrates consists of 59 and $63 \mathrm{kDa}$ proteins, a finding in exact agreement with our own. Our present results show that the 2 most widely used antisera to GAD strongly rccognize the proteins purified on GAD- 1 columns. Thus, the antigens used to produce these antisera are either very similar or identical to the group of proteins immunoprecipitated by GAD-1. Two results suggest that the proteins recognized by
GAD-1 are homologous to the protein coded for by the feline cDNA of Kaufman et al. (1986). The first is the sequence homology discussed above; the second is the fact that a $\lambda \mathrm{GT}-11$ fusion protein coded for by this cDNA is also recognized by the antibodies of Roberts' and Oertel's group. Thus, on the basis of biochemical and immunological criteria, all of the cited papers seem to study highly related or identical proteins. Recently, Wu et al. (1986) and Denner et al. (1987) proposed that highly purified GAD from the rat brain consists of proteins of 40 and $80 \mathrm{kDa}$. There are 2 possible ways to explain the difference between these results and those obtained by others. One is that the 40 and $80 \mathrm{kDa}$ proteins are alternative forms of the GAD proteins described here and by other laboratories. On the other hand, the 40 and $80 \mathrm{kDa}$ proteins may be products of a distinct gene or genes that have the property of GAD enzymatic activity but have no sequence homology to the proteins studied in this report.

What is the relationship of the multiple bands purified on the GAD-1 column to one another? The fact that GAD-6 binds to the $59 \mathrm{kDa}$ band and the lower-molecular-weight bands suggests that these are related to one another. Since the $63 \mathrm{kDa}$ protein is not recognized hy GAD-6, it must lack at least one epitope found on the lower bands. Two widely differing possibilities are that the 59 and $63 \mathrm{kDa}$ proteins are unrelated by sequence but tightly associated physically, and hence copurified. Alternatively, they might be highly related sequences. If so, their relationship to the variants of GAD described by Martin and his coworkers (Spink et al., 1983, 1985) will be interesting to elucidate. A final, crucial question has not been answered by this study. Each highly enriched fraction of GAD has several proteins and enzymatic activity. Which of these polypeptides is actually catalytically active cannot be determined from the present data and can only be resolved by separating the proteins by means that preserve enzymatic activity.

\section{References}

Bradford, M. (1976) A rapid and sensitive method for the quantitation of microgram quantities of protein utilizing the principle of proteindye binding. Anal. Biochem. 72: 248-254.

Chang, Y. C., and D. I. Gottlieb (1987) Characterization of rat brain glutanic acid decarboxylase. Soc. Neurosci. Abstr. 13: 571.

Denner, L. A., S. C. Wei, H. S. Lin, C.-T. Lin, and J. Y. Wu (1987) Brain L-glutamate decarboxylase: Purification and subunit structure. Proc. Natl. Acad. Sci. USA 84: 668-672.

Fisher, R. S., M. S. Levine, A. M. Adinolfi, C. D. Hull, and N. A. Buchwald (1987) The morphogenesis of glutamic acid decarboxylase in the neostriatum of the cat: Neuronal and ultrastructural localization. Dev. Brain Res. 33: 215-234.

Fonnum, F. (1968) The distribution of glutamate decarboxylase and aspartate transaminase in subcellular fractions of rat and guinea-pig brain. Biochem. J. 106: 401-412.

Gottlieb, D. I., Y.-C. Chang, and J. E. Schwob (1986) Monoclonal antibodies to glutamic acid decarboxylase. Proc. Natl. Acad. Sci. USA 83: 8808-8812.

Hunkapiller, M. W., E. Lujan, F. Ostrander, and L. E. Hood (1983) Isolation of microgram quantities of proteins from polyacrilamide gels for amino acid sequence analysis. Methods Enzymol. 91: 227236 .

Kaufman, D. L., J. F. McGinnis, N. R. Krieger, and A. J. Tobin (1986) Brain glutamate decarboxylase cloned in $\mathrm{gt}$-11: Fusion protein produces gamma-aminobutyric acid. Science 232: 1138-1140.

Kobayashi, Y., D. L. Kaufman, and A. J. Tobin (1987) Glutamic acid decarboxylase cDNA: Nucleotide sequence encoding an enzymatically active fusion protein. J. Neurosci. 7: 2768-2772.

Laemmli, U. K. (1970) Cleavage of structural proteins during the assembly of the head of bactcriophage T4. Nature 227: 680-685.

Legay, F., S. Pelhati, and M. L. Tappaz (1986) Phylogenesis of brain 
glutamic acid decarboxylase from vertebrates: Immunochemical studies. J. Neurochem. 46: 1478-1486.

Legay, F., S. Henry, and M. Tappaz (1987a) Evidence for two distinct forms of native glutamic acid decarboxylase in rat brain soluble extract: An immunoblotting study. J. Neurochem. 48: 1022-1026.

Legay, F., S. Henry, and M. L. Tappaz (1987b) Monoclonal antibodies against rat brain glutamic acid decarboxylase. Neurochem. Int. 10 : 287-294.

McLaughlin, B. J., J. G. Wood, K. Saito, E. Roberts, and J.-Y. Wu (1975) The fine structural localization of glutamate decarboxylase in developing axonal processes and presynaptic terminals of rodent cerebellum. Brain Res. 85: 355-371.

Molinoff, P. B., and E. A. Kravitz (1968) The metabolism of $\gamma$-aminobutyric acid (GABA) in the lobster nervous system - glutamic decarboxylase. J. Neurochem. 15: 391-409.

Oertel, W. H., D. E. Schmechel, M. L. Tappaz, and I. J. Kopin (1981) Production of a specific antiserum to rat brain glutamic acid decarboxylase by injection of an antigen-antibody complex. J. Neurosci. 6: $2689-2700$.

Roberts, E., and D. G. Simonsen (1963) Some properties of L-glutamic decarboxylase in mouse brain. Biochem. Pharmacol. 12: 113-134.

Saito, K., R. Barber, J. Y. Wu, T. Matsuda, E. Roberts, and J. Vaughn (1974) Immunohistochemical localization of glutamic acid decarboxylase in rat cerebellum. Proc. Natl. Acad. Sci. USA 71: 269-273.
Schwob, J. E., and D. I. Gottlieb (1986) The primary olfactory projection has two chemically distinct zones. J. Neurosci. 6: 3393-3404.

Spink, D. C., S. J. Wu, and D. L. Martin (1983) Multiple forms of glutamate decarboxylase in porcine brain. J. Neurochem. 40:11131119.

Spink, D. C., T. G. Porter, S. J. Wu, and D. L. Martin (1985) Characterization of three kinetically distinct forms of glutamate decarboxylase from pig brain. Biochem. J. 231: 695-703.

Weinstein, H., E. Roberts, and T. Kakefuda (1963) Studies of subcellular distribution of $\gamma$-aminobutyric acid and glutamic decarboxylase in mouse brain. Biochem. Pharmacol. 12: 503-509.

Wu, J. Y. (1976) Purification, characterization and kinetic studies of GAD and GABA-T from mouse brain. In GABA in Nervous System Function, E. Roberts, T. N. Chase, and D. B. Tower, eds., pp. 7-56, Raven, New York.

Wu, J. Y., T. Matsuda, and E. Roberts (1973) Purification and characterization of glutamate decarboxylase from mouse brain. J. Biol. Chem. 248: 3029-3034.

Wu, J. Y., L. A. Denner, S. C. Wei, C.-T. Lin, G.-X. Song, Y. F. Xu, J. W. Liu, and H. S. Lin (1986) Production and characterization of polyclonal and monoclonal antihodies to rat brain L-glutamate decarboxylase. Brain Res. 373: 1-14. 